Original Research Paper

\title{
Pengenalan Digital Marketing dan Inovasi Produk “Jeger" Guna Mendukung Pemasaran dan Peningkatan Mutu Kerupuk Singkong di Kel. Geres, Kec. Labuhan Haji, Kab. Lombok Timur
}

\author{
Khairul Mustain ${ }^{1}$, Novi Safitri ${ }^{2}$, Nurifansyah ${ }^{3}$, Achmad Munajab $^{4}$, Nyayu Siti Fahira ${ }^{5}$, Muhammad \\ Khairul Fatihin', Asmawati ${ }^{6}$, Yasmiati ${ }^{6}$, Muhammad Salikin ${ }^{7}$, Muhammad Izzul Islam ${ }^{8}$, Winda \\ Hasri Meutiya', Satrijo Saloko ${ }^{10 *}$ \\ ${ }^{1}$ Prodi Agribisnis, Universitas Mataram, Mataram, Indonesia; \\ ${ }^{2}$ Prodi Peternakan, Universitas Mataram, Mataram, Indonesia; \\ ${ }^{3}$ Prodi Prodi Budidaya Perairan, Universitas Mataram, Mataram, Indonesia; \\ ${ }^{4}$ Prodi Prodi Agribinis, Universitas Mataram, Mataram, Indonesia \\ ${ }^{5}$ Prodi Informatika, Universitas Mataram, Mataram, Indonesia; \\ ${ }^{6}$ Prodi Manajemen, Universitas Mataram, Mataram, Indonesia; \\ ${ }^{7}$ Prodi Ilmu Hukum, Universitas Mataram, Mataram, Indonesia \\ ${ }^{8}$ Prodi Teknik Sipil, Universitas Mataram, Mataram, Indonesia; \\ ${ }^{9}$ Prodi Sosiologi, Universitas Mataram, Mataram, Indonesia \\ ${ }^{10}$ Prodi Ilmu dan Teknologi Pangan, Universitas Mataram, Mataram, Indonesia
}

https://doi.org/10.29303/jpmpi.v3i2.973

Sitasi: Mustain, K., Safitri, N., Nurifansyah., Munajab, A., Fahira, N. S., Fatihin, M. K., Asmawati., Yasmiati., Salikin, M., Islam, M. I., Meutiya, W. H \& Saloko, S. (2021). Pengenalan Digital Marketing dan Inovasi Produk "Jeger" Guna Mendukung Pemasaran dan Peningkatan Mutu Kerupuk Singkong di Kel. Geres, Kec. Labuhan Haji, Kab. Lombok Timur. Jurnal Pengabdian Magister Pendidikan IPA, 4(3)

\section{Article history}

Received: 31 Agustus 2021

Revised: 19 September 2021

Accepted: 21 September 2021

*Corresponding Author: Satrijo Saloko, Prodi Ilmu dan Teknologi Pangan, Universitas Mataram,

Mataram, Indonesia

Email: s_saloko@unram.ac.id
Abstract: Kelurahan Geres merupakan salah satu Kelurahan yang terletak di Kecamatan Labuhan Haji, Kabupaten Lombok Timur, Nusa Tenggara Barat. Mata pencaharian dari masyarakat Kelurahan Geres berkaitan dengan pengelolaan tambang batu apung, dan pasir, selain hal ini terdapat juga bisnis kuliner yang khas dari Kelurahan ini, yaitu keripik singkong yang dinamakan JEGER ( Jeje Geres ). Jeger merupakan keripik yang terbuat dari singkong asli. Mengenai bisnis ini masih terdapat banyak kekurangan dari segi pemasaran dan juga kesiapan Kelompok pengelola dalam meningkatkan pemasaran dan inovasi dari produk ini sehingga KKN Kelurahan Geres 2021 dengan tema pengenalan Digital marketing dan inovasi produk guna mendukung pemasaran serta meningkatkan kualitas produk dari kelompok JBL (Jeger Buana Lombok). Tujuan pertama dalam kegiatan KKN ini adalah memberikan pelatihan yang berkaitan dengan pemasaran di bidang online atau yang lebih dikenal dengan kegiatan Digital Marketing yang diharpakan dapat mendongrak sistem pemasaran dari kelompok ini. Selain pengenalan secara luas terkait dengan Digital Marketing cangkupan cangkupan pelatihan di dalam Digital Marketing ini juga berkaitan dengan pengenalan aplikasi yang digunakan di dalam pemasaran online, selain itu juga diberikan pelatihan fotografi, videografi, serta desain grafis. Tujuan yang kedua berkaitan dengan perbaikan nilai ekonomi melalui perbaikan logo, kemasan dan juga inovasi beberapa varian rasa dari usaha Jeger.

Keywords: olahan singkong, digital marketing, perbaikan kemasan, Inovasi rasa. 


\section{Pendahuluan}

Produk " JEGER " atau biasa disebut dengan Jeje Geres merupakan produk khas Kelurahan Geres yang dikembangkan oleh KKN Tematik UNRAM 2021 di Kelurahan Geres, dalam program KKN New Normal, dengan tema pengenalan digital marketing dan inovasi produk guna mendukung pemasaran serta meningkatkan kualitas produk dari kelompok JBL (Jeger Buana Lombok ). JEGER merupakan krupuk yang terbuat dari singkong asli tanpa ada bahan baku pembantu lainnya. Produk ini termasuk produk camilan yang khas, gurih, dan dan tidak berminyak setelah penggorangan, selain itu JEGER sangat cocok dikonsumsi untuk semua kalangan usia karena produk ini merupakan produk yang aman dan juga sangat murah untuk terjangkau konsumen.

Kelurahan Geres merupakan salah satu Kelurahan dari 4 Kelurahan di wilayah Kecamatan Labuhan Haji, Lombok Timur, Nusa Tenggara Barat dengan jumlah penduduk 3.947 jiwa terdiri dari 1.937 jiwa laki-laki dan 2010 jiwa perempuan dengan jumlah kepala keluarga sebanyak 1.263 KK. Kelurahan Geres memiliki lahan yang cukup luas yaitu 565,590 Ha meliputi 5 Lingkungan dan 15 RT masing-masing Lingkungan.

Kegiatan perekonomian di Kelurahan Geres dalam dua tahun terakhir sejak tahun 2018-2019 mengalami peningkatan yang cukup menggembirakan, dan berimplikasi bagi peningkatan pendapatan Masyarakat. Kegiatan ekonomi masyarakat masih didominasi salah satunya pada bidang bisnis kuliner. Salah satu bisnis kuliner yang ada di Kelurahan Geres yakni kerupuk singkong, Masyarakat sering menyebutnya "JEGER (Jeje Geres)". Namun pada masa pandemi saat ini bisnis kuliner ini mengalami penurunan pendapatan.

Bisnis kuliner termasuk bisnis yang terbilang sulit dijalanakan, terlebih dengan SDM di Kelurahan Geres yang masih di bawah rata-rata. Oleh karena itu, tidak jarang usaha kuliner di Kelurahan Geres mengalami kebangkrutan (tidak berkelanjutan). Maka dari itu penulis memilih untuk menciptakan kegiatan pengenalan digital marketing dan sekaligus mengembangkan usaha JEGER dengan memberikan inovasi di bidang pengemasan, pemasaran, dan produksi, dan bidang lain seiring berjalannya program KKN. Dikarenakan JEGER merupakan usaha yang sudah ada sejak puluhan tahun yang lalu dan merupakan salah satu kudapan yang bahan bakunya kaya akan gizi dan mineral, yang tentunya jika diolah secara efisien bisa memberikan dampak yang positif kepada masyarakat sekitar.

Tujuan dari pengenalan digital marketing dan sekaligus mengembangkan usaha JEGER dengan memberikan inovasi di bidang pengemasan, pemasaran, dan produksi adalah untuk guna mendukung usaha masyarakat Kelurahan Geres berdasarkan dengan besarnya potensi jajanan JEGER jika dikembangkan, sehingga kelompok KKN Kelurahan Geres memberikan pengenalan digital marketing melalui kegiatan seperti workshop dan pelatihan digital marketing yang dikemas dengan sedemikian rupa sehingga materi yang disampaikan bisa mudah diserap oleh masyarakat. Kegiatan workshop dan pelatihan yang dilakukan guna mendukung sistem pemasaran produk JEGER yang saat ini sedang terpengaruh karena adanya Covid-19, sehingga digital marketing merupakan salah satu cara yang bisa diterapkan oleh kelompok JBL dalam memasarkan produk mereka. Kegiatan ini juga didukung dengan adanya kuesioner dan modul untuk setiap pertemuan yang diberikan kepada peserta untuk menunjang proses pelatihan yang diberikan oleh kelompok KKN Kelurahan Geres. Kegiatan workshop dan pelatihan yang dilakukan disambut dengan antusias oleh masyarakat dan Lurah beserta staff Kelurahan Geres.

Selain dari pengenalan digital marketing seperti workshop dan pelatihan digital marketing, adalah dengan pengembangan dari segi pengemasan, inovasi rasa, dan logo. Adanya pengembangan dari segi pengemasan, inovasi rasa, dan logo adalah untuk menarik perhatian konsumen sehingga tertarik untuk membeli produk JEGER karena adanya kemasan dan logo yang menarik perhatian masyarakat luas. Inovasi rasa yang diberikan dari kelompok KKN kepada kelompok JBL adalah berupa rasa original, sapi panggang, barbeque, dan balado. Yang dimana setiap bungkus JEGER dijual dengan harga sekitar Rp. $8.000 \mathrm{~s} / \mathrm{d}$ Rp. 10.000 tergantung dengan berat produk.

\section{Metode}

Dalam pelaksanaan kegiatan KKN, tahap awal yang dilakukan adalah meminta izin kepada Kepala Lurah Geres untuk melaksanakan kegiatan 
KKN di lingkungan Kelurahan Geres dengan tema Kewirausahaan, sekaligus berdiskusi tentang potensi sumber daya alam atau usaha yang bisa dikembangkan di Kelurahan Geres, melakukan observasi lingkungan Kelurahan Geres dan mengidentifikasi masalah yang ada. Setelah itu ditemukan ide untuk mengembangkan salah satu usaha masyarakat, yaitu keripik "JEGER" yang berbahan dasar singkong, yang mana singkong juga merupakan bahan yang mudah ditemukan di Geres. Selanjutnya dilakukan survey terkait usaha "JEGER" secara lebih lanjut, diawali dengan mendatangi pabrik pembuatan "JEGER" yang masih memakai alat-alat sederhana, dilanjutkan dengan mengikuti kegiatan pelatihan untuk mengembangkan produksi keripik "JEGER" yang juga merupakan salah satu project dari Dosen Pembimbing Lapangan KKN Kelurahan Geres. Setelah itu ditentukan untuk mengembangkan usaha "JEGER" dari suatu kelompok usaha "Jeger Buana Lombok (JBL)" dalam bidang pemasaran dengan memanfaatkan metode digital marketing dan memberikan inovasi seperti logo, pengemasan produk, dan inovasi rasa.

Setelah itu ditentukan untuk mengembangkan usaha "JEGER" dari suatu kelompok usaha "Jeger Buana Lombok (JBL)" dalam bidang pemasaran dengan memanfaatkan metode digital marketing dan memberikan inovasi seperti desain logo, desain kemasan dan pengemasan produk, dan inovasi rasa. Kemudian membuat akun FaceBook kelompok "JBL" untuk memasarkan produk yang ada. Dilakukan workshop dan pelatihan digital marketing guna mendukung sistem pemasaran serta meningkatkan kualitas produk JBL.

Indikator yang digunakan untuk menentukan keberhasilan pelaksanaan kegiatan KKN tema Kewirausahaan di Kelurahan Geres adalah sebagai berikut:

1. Terlaksananya workshop dan pelatihan digital marketing untuk mendukung sistem pemasaran serta meningkatkan kualitas produk JBL.

2. Peserta sosialisasi dan workshop mampu mengaplikasikan hasil yang didapat dari workshop dan pelatihan yang dilakukan.

\section{Hasil dan Pembahasan}

\section{a. Observasi lokasi}

Tujuan dari observasi lokasi yaitu agar mengetahui permasalahan yang ada di Lingkungan Kelurahan Geres yang berkaitan dengan tema kewirausahaan, dan agar mendapatkan izin untuk menjalankan program yang telah dibuat di lingkungan sekitar. Bentuk kegiatan dari observasi lokasi yaitu mengantar surat izin sekaligus meminta izin melakukan kegiatan KKN di Kelurahan Geres yang akan dilaksanakan pada tanggal 21 Juni 2021. Kami bertemu dengan Kepala Lurah Kelurahan Geres dan Sekertaris Lurah Kelurahan Geres, kemudian kami berdiskusi dengan Beliau disana terkait permasalahan yang ada di masyarakat dan yang dapat kami kembangkan nanti sewaktu melakukan kegiatan KKN yang menyangkut dengan tema kewirausahaan yang telah kami programkan. Setelah mengetahui bahwa di daerah Kelurahan Geres terdiri dari lima lingkungan dan wilayahnya banyak terdapat tumbuhan singkong serta adanya usaha masyarakat yang dirasa perlu untuk dikembangkan, maka kelompok KKN Kelurahan Geres mendapatkan gagasan untuk mengembangkan salah satu usaha masyarakat setempat yaitu keripik "JEGER" yang bahan dasarnya terbuat dari singkong.

b. Workshop dan Pelatihan Digital Marketing

Kegiatan workshop dan pelatihan yang dilakukan guna mendukung sistem pemasaran produk JEGER yang saat ini sedang terpengaruh karena adanya Covid-19, sehingga digital marketing merupakan salah satu cara yang bisa diterapkan oleh kelompok JBL dalam memasarkan produk mereka (Gambar 1). Kegiatan ini juga didukung dengan adanya kuesioner dan modul untuk setiap pertemuan yang diberikan kepada peserta untuk menunjang proses pelatihan yang diberikan oleh kelompok KKN Kelurahan Geres. Setiap kegiatan berakhir, peserta diberikan studi kasus dan kemudian diperiksa bersama di pertemuan berikutnya. Kegiatan workshop dan pelatihan yang dilakukan disambut dengan antusias oleh masyarakat dan Lurah beserta staf Kelurahan Geres. 
1) Workshop Digital Marketing

a) Kuesioner

Dalam pelaksanaan workshop digital marketing dilakukan dua kali pengisian kuesioner oleh peserta workshop, yaitu kuesioner yang diisi di
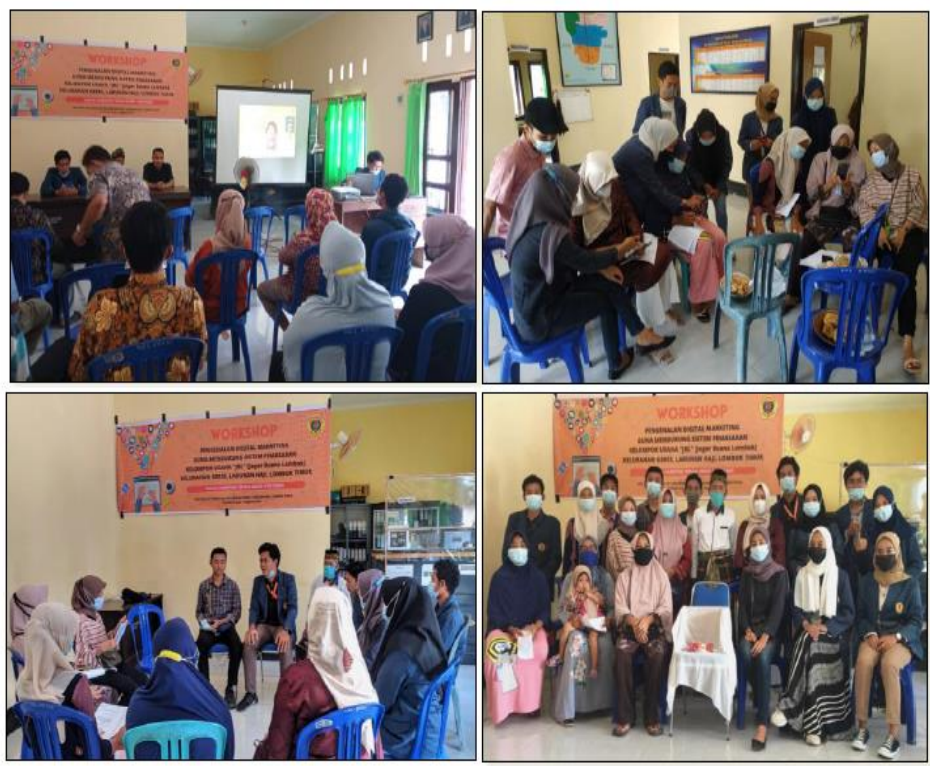

Gambar 1. Kegiatan Wokshop Digital Marketing Kelompok JBL

Tabel 1. Kuesioner peserta di awal kegiatan workshop

\begin{tabular}{|l|l|l|l|l|l|l|}
\hline \multirow{2}{*}{ No. } & \multicolumn{1}{|c|}{ Pernyataan } & \multicolumn{5}{c|}{ Respon } \\
\cline { 2 - 7 } 1. & $\begin{array}{l}\text { Saya sudah mendengar atau mengetahui } \\
\text { tentang Digital Marketing sebelumnya. }\end{array}$ & & 3 & 5 & 5 & SS \\
\hline 2. & $\begin{array}{l}\text { Saya tertarik untuk mempunyai atau sudah } \\
\text { mempunyai media sosial. }\end{array}$ & 2 & 5 & 6 & \\
\hline 3. & $\begin{array}{l}\text { Saya sudah mengetahui cara menggunakan } \\
\text { media sosial sebagai sarana untuk } \\
\text { mempromosikan suatu produk. }\end{array}$ & 6 & 5 & 2 & \\
\hline 4. & $\begin{array}{l}\text { Saya sudah mengetahui tentang fungsi dasar } \\
\text { dari Digital Marketing. }\end{array}$ & 6 & 5 & 2 & \\
\hline 5. & $\begin{array}{l}\text { Saya sudah pernah menerapkan sistem Digital } \\
\text { Marketing di dalam bisnis saya (jika ada). }\end{array}$ & 7 & 4 & 2 & \\
\hline 6. & $\begin{array}{l}\text { Saya sudah pernah berniat untuk } \\
\text { mempromosikan bisnis saya di media sosial. }\end{array}$ & 6 & 4 & 3 & \\
\hline 7. & $\begin{array}{l}\text { Promosi suatu produk di media sosial (seperti } \\
\text { facebook, instagram, blog, dll.) menarik } \\
\text { perhatian saya. }\end{array}$ & & 5 & 8 & \\
\hline 8. & $\begin{array}{l}\text { Saya membeli suatu produk karena melihat } \\
\text { promosi di media sosial. }\end{array}$ & 6 & 5 & 2 & \\
\hline 9. & $\begin{array}{l}\text { Saya tertarik untuk mempelajari tentang } \\
\text { Digital Marketing lebih dalam lagi. }\end{array}$ & 2 & 5 & 7 & \\
\hline 10. & Saya tertarik untuk menerapkan konsep & & & 3 & 10 & \\
\hline
\end{tabular}


Tabel 2. Kuesioner peserta di akhir kegiatan workshop

\begin{tabular}{|c|c|c|c|c|c|c|}
\hline \multirow{2}{*}{ No. } & \multirow{2}{*}{ Pernyataan } & \multicolumn{5}{|c|}{ Respon } \\
\hline & & STS & TS & KS & $\mathbf{S}$ & SS \\
\hline 1. & $\begin{array}{l}\text { Saya sudah mendengar atau mengetahui } \\
\text { tentang Digital Marketing sebelumnya. }\end{array}$ & & & & 11 & 2 \\
\hline 2. & $\begin{array}{l}\text { Saya tertarik untuk mempunyai atau sudah } \\
\text { mempunyai media sosial. }\end{array}$ & & & & 10 & 3 \\
\hline 3. & $\begin{array}{l}\text { Saya sudah mengetahui cara menggunakan } \\
\text { media sosial sebagai sarana untuk } \\
\text { mempromosikan suatu produk. }\end{array}$ & & & & 12 & 1 \\
\hline 4. & $\begin{array}{l}\text { Saya sudah mengetahui tentang fungsi } \\
\text { dasar dari Digital Marketing. }\end{array}$ & & & & 11 & 2 \\
\hline 5. & $\begin{array}{l}\text { Saya sudah pernah menerapkan sistem } \\
\text { Digital Marketing di dalam bisnis saya (jika } \\
\text { ada). }\end{array}$ & & & 9 & 4 & \\
\hline 6. & 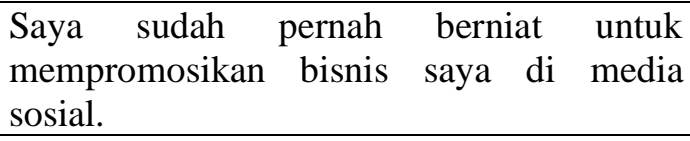 & & & & 10 & 3 \\
\hline 7. & $\begin{array}{l}\text { Promosi suatu produk di media sosial } \\
\text { (seperti facebook, instagram, blog, dll.) } \\
\text { menarik perhatian saya. }\end{array}$ & & & & 1 & 12 \\
\hline 8. & $\begin{array}{l}\text { Saya membeli suatu produk karena melihat } \\
\text { promosi di media sosial. }\end{array}$ & & & 8 & 3 & 2 \\
\hline 9. & $\begin{array}{l}\text { Saya tertarik untuk mempelajari tentang } \\
\text { Digital Marketing lebih dalam lagi. }\end{array}$ & & & & 9 & 4 \\
\hline 10. & $\begin{array}{l}\text { Saya tertarik untuk menerapkan konsep } \\
\text { Digital Marketing di dalam bisnis saya. }\end{array}$ & & & & 1 & 12 \\
\hline
\end{tabular}

c. Inovasi produk JBL (Jeger Buana Lombok)

1) Produk (Kemasan dan Rasa)

Inovasi produk yang diberikan oleh kelompok KKN Kelurahan Geres kepada produk JBL adalah berupa kemasan produk dan inovasi rasa. Kemasan produk bisa dilihat pada Gambar 2, sedangkan untuk rasa, selain rasa original diberikan inovasi rasa barbeque, balado, dan sapi panggang. Tujuan dari inovasi kemasan dan rasa keripik JEGER adalah untuk meningkatkan kualitas produk JBL dari segi rasa dan kemasan agar masyarakat luas bisa lebih tertarik dalam memilih keripik JEGER sebagai camilan sehari-hari.

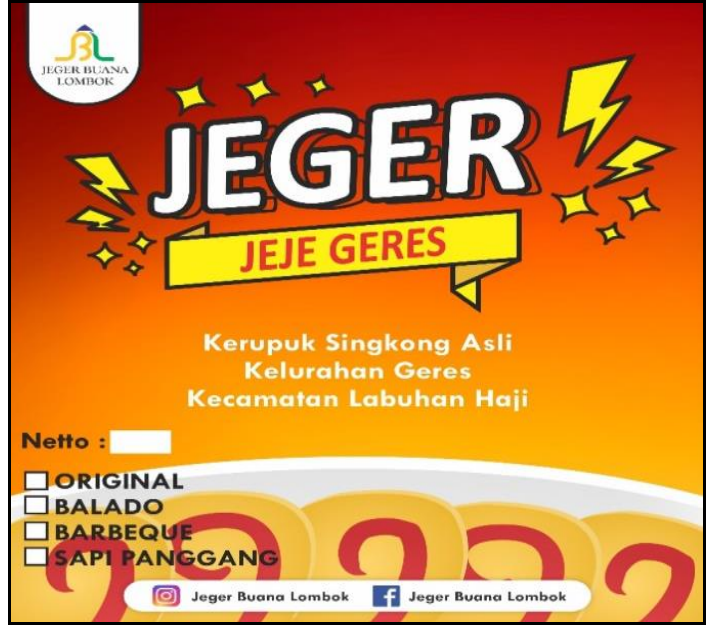

Gambar 2. Kemasan produk JEGER. 
2) Pembuatan Logo

Tujuan dari pembuatan logo adalah sebagai salah satu proses branding dan strategi marketing dalam memasarkan produk dari JBL agar diterima oleh masyarakat luas, karena fungsi logo pada suatu usaha adalah sebagai simbol pengingat produk bagi konsumen [6]. Penggunaan logo pada kemasan JEGER akan membantu konsumen mengingat produk buatan dari JBL atau Jeger Buana Lombok. Logo yang diberikan bisa dilihat pada Gambar 3, yang mana mempunyai filosofi sebagai berikut:

- Warna biru: meninggalkan kesan tenang, damai, dan bertanggung jawab serta kepercayaan. Seperti halnya kelompok JBL yang membangun kepercayaan kepada konsumen terkait dengan produk yang dipasarkan.

- Warna kuning: warna kegembiraan dan harapan. Di dalam desain logo, warna kuning meninggalkan kesan kebahagiaan dan kejayaan.

- Warna hijau: diartikan sebagai sumber kehidupan, kesegaran, dan rasa aman.

- Bentuk lumbung pada warna biru: simbolis untuk bangunan lumbung khas Suku Sasak, yaitu bangunan penyimpanan bahan pangan.

- Tulisan "JEGER BUANA LOMBOK”: menandakan bahwa logo tersebut adalah logo dari kelompok "Jeger Buana Lombok"

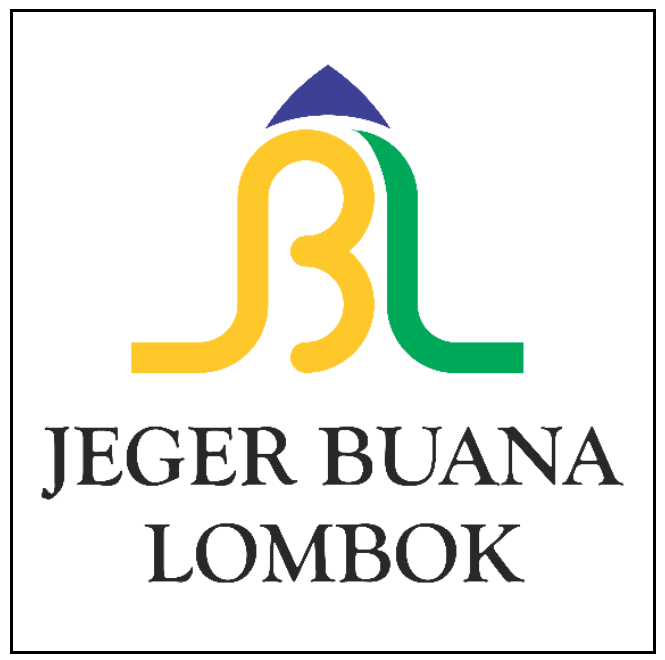

Gambar 3. Logo Jeger Buana Lombok

\section{Kesimpulan}

Dari hasil selama 30 hari di Kelurahan Geres, dapat ditarik kesimpulan bahwa dari program inti $\mathrm{KKN}$ untuk program pengenalan digital marketing kelompok JBL (Jeger Buana Lombok ) sangat anutusias dalam mengikuti kegitan tersebut yang dapat dilihat bersama dari hasil kuisioner yang sudah dibagikan. Selaian dari itu hasil inovasi produk dari kemasan dan juga logo dapat diterima dengan baik oleh Kelompok JBL dan juga Masyarakat sekitar, dari adanya inovasi ini dapat dijadikan sebagai perabaikan nilai ekonomi untuk produk JEGER ( Jeje Geres ) ini sendiri dan diharapkan mampu menjadi bahan pembelajaran untuk masyarakat sehingga akan muncul inovasi inovasi baru lain kedepannya.

\section{Ucapan Terima Kasih}

Ucapan terima kasih dan apresiasi yang sebesar-besarnya kepada Tuhan Yang Maha Esa, karena berkat rahmat dan karunianyalah sehingga terciptanya artikel ilmiah ini. Tidak lupa pula ucapan terima kasih kepada Dosen Pendamping Lapangan yang selalu membimbing dan mengarahkan kami sehingga kami mampu berada pada tahap ini, dan juga kepada tim KKN Tematik UNRAM, Kelurahan Geres 2021 dengan tema pengenalan digital marketing dan inovasi produk guna mendukung pemasaran serta meningkatkan kualitas produk dari kelompok JBL (Jeger Buana Lombok)

\section{Daftar Pustaka}

A.K. Patoki et al., "Analisis Profitabilitas Keripik Singkong Pada Industri RumaH Tangga,vol. 5, no. 1, pp. 77-85, 2017.

\section{A.R.Nugroho,"PENGARUH LOGO DESIGN LOGO BARU BUMD YANG BERBASISKAN KEARIFAN LOKAL TERHADAP CITRA PERUSAHAAN (Studi Kuantitatif Mengenai Perubahan Logo Baru pada PDAM Kota Bandung)," J. Ilm. Komun. Makna, vol. 5, no. 1, p. 1, 2015, doi: 10.30659/jikm.5.1.1-15.}

K. Geres, Profil Kelurahan Geres. Lombok Timur: Kelurahan Geres, 2019.

M. T. Febriyantoro and D. Arisandi, "Pemanfaatan 
Digital Marketing Bagi Usaha Mikro, Kecil Dan Menengah Pada Era Masyarakat Ekonomi Asean," JMD J. Ris. Manaj.

Bisnis Dewantara, vol. 1, no. 2, pp. 61-76, 2018, doi: 10.26533/jmd.v1i2.175.

Muntoha, Jamroni, and R. U. Ummayah, "Pelatihan Pemanfaatan dan Pengolahan Singkong Menjadi Makanan Ringan Tela Rasa," J. Inov. dan Kewirausahaan, vol. 4, no. 3, pp 188-193, 2015.

V. I. Septiriyani, "Potensi Pemanfaatan Singkong (Manihot utilissima) Sebagai Bahan Tambahan 